\title{
An Exploration of Calculus Students' Beliefs about Mathematics
}

\author{
Abraham Ayebo ${ }^{1 *}$, Amaniel Mrutu ${ }^{1}$ \\ ${ }^{1}$ University of Minnesota, USA \\ * CORRESPONDENCE: $\square$ aayebo@r.umn.edu
}

\begin{abstract}
This study explored the mathematics beliefs of students enrolled in a first year calculus class at a Midwestern university in the United States. The Indiana Mathematics Belief Scale was administered to 162 students enrolled in a first year calculus class during the first week of school. An exploratory factor analysis (EFA) was performed to examine the factor structure of the survey instrument. Five factors were extracted: Effort, Usefulness, Difficult problems, Understanding, and Steps. Students' responses were analyzed for inter-item correlation and internal consistency reliability (Cronbach's $\alpha$ ). The results were compared with similar studies conducted by Kloosterman and Stage (1992) as well as Berkaliev and Kloosterman (2009). The reliability obtained in this study was consistent with the previous studies. In particular, the Steps subscale was quite low (0.52). It might therefore make sense to drop the Steps subscale in future studies.
\end{abstract}

Keywords: mathematics, mathematics beliefs, problem solving, calculus students

\section{INTRODUCTION}

The past three decades have witnessed several studies on students' beliefs. These studies have focused on students perspectives on the nature of knowledge and how knowledge is constructed (see, for example, Pintrich, 2002; Pehkonen \& Hannula, 2004). Scholars do not have a clear-cut definition of the construct of belief (Furinghetti \& Pehkonen, 2002; McLeod, 2002; Pehkonen \& Hannula, 2004). This has created some confusion in the literature. For example, while some scholars use the term belief to refer to belief and knowledge (Cross, 2009), others use it to imply affective issues such as attitudes, values, and emotions (McLeod, 1992). Studies that relate to the latter interpretation of beliefs point to an interesting relationship between cognitive and affective mathematical domains. Ma and Kishor (1997) posited that there exists "a cognitive component to every affective objective and an affective component to every cognitive objective" (p.26) and this suggests that any investigation into reasons for non-participation in mathematics must include an examination of both affective and cognitive domains. Other scholars such as McLeod (1992) noted that student beliefs about mathematics can be classified into four categories: the difficulty and rule-based nature of mathematics; the self and self-confidence in learning mathematics and attributions for failure or success; how mathematics should be taught; and the social context for learning mathematics.

An equally strongly reported emotional response towards mathematics is that of mathematics anxiety (Ma, 1999). Anxiety has been shown to have negative effects on mathematics achievement as a consequence of an associated reduction in working memory (Maloney, Schaeffer, \& Beilock, 2013) with obvious impacts on performance in high stakes testing. Although significant research into beliefs and attitudes on mathematics have been conducted, much of this reported research concerns adults (Vanayan, White, Yuen, \& Teper, 1997), despite the fact that negative attitudes towards mathematics appear to have their origin very early in formal schooling. What is needed is an extended investigation into when the first signs of mathematical withdrawals

Article History: Received 1 January $2019 \bullet$ Revised 18 January $2019 \bullet$ Accepted 26 January 2019

(C) 2019 by the authors; licensee Modestum Ltd., UK. Open Access terms of the Creative Commons Attribution 4.0 International License (http://creativecommons.org/licenses/by/4.0/) apply. The license permits unrestricted use, distribution, and reproduction in any medium, on the condition that users give exact credit to the original author(s) and the source, provide a link to the Creative Commons license, and indicate if they made any changes. 
occur to determine how the mathematically curious becomes a mathematically indifferent student, and how this dislike of mathematics may be averted, or at least minimized (Di Martino \& Zan, 2010).

The study of mathematics encompasses the ability to recognize mathematics as a multifaceted subject with interconnected concepts that can be applied to a range of practical circumstances. Mathematical beliefs that have an adverse effect on how students understand mathematical concepts disaffirm the assumptions about the nature of mathematics. There is a connection between being able to understand mathematics and being able to think mathematically. Schoenfeld (1988) noted that mathematical thinking "consists not only of mastering various facts and procedures, but also in understanding connections among them; and thinking mathematically also consists of being able to apply one's formal mathematical knowledge flexibly and meaningfully in situations for which the mathematics is appropriate" (p. 164).

Several studies have shown that students' mathematical self-concepts are highly correlated with their performance on mathematical tasks. For example, Pajares and Graham (1999) noted that mathematics selfefficacy was significantly related with mathematics achievement of students in middle school. House (1995) also found that students with higher academic self-concept generally earned higher grades in mathematics courses while controlling for the effect of prior achievement. A study by Wheat, Tunnel, \& Munday (1991) found that students' self-concept was significantly related to their final grade.

Many scholars have conducted research on how students' belief about mathematics impact their motivation for and performance in mathematical tasks. Some of these have used qualitative methods, some quantitative, and others a mixture of both. Several instruments have been used, such as the FenemmaSherman mathematical attitude scale (Barrow \& Wood 2006), the Mathematical Thinking Rating Scale (Kargar, Tarmizi, \& Bayat, 2010), Mathematics Attitude Inventory (Sandman, 1979), and Mathematics Anxiety Questionnaire (Meece, Wigfield, \& Eccles,1990). In this paper, the relatively recent scale, the Indiana Mathematics Belief Scale, designed by Kloosterman and Stage (1992), was used to measure the beliefs of students taking a first year calculus class.

\section{METHOD}

\section{Participants}

The participants in the study were 163 students enrolled in first year Calculus (Calculus I) at a land-grant university in the Midwestern United States during the fall of 2015. Among the 163 students, 1 student did not complete the entire survey, so that response was not included in the study. Of the remaining 162 participants, $24(14.8 \%)$ were male, $138(85.2 \%)$ were female, 6 (3.7\%) majored in mathematics, $121(74.7 \%)$ majored in engineering, 4 (2.5\%) majored in chemistry, and 31(19.1\%) had a major other than mathematics, engineering or chemistry.

\section{Procedure}

At the beginning of the spring 2015 semester, instructors of Calculus 1 were contacted for permission to administer the mathematical belief questionnaire to students in their classrooms. This was after the Institutional Review Board (IRB) approval had been received. Consent forms were signed by students who agreed to participate in the study. No data were collected from students who did not sign the consent forms. Participants were asked to rate the degree to which they agreed to each item on the survey questionnaire. They were informed that how they completed the survey will not affect their course grade. The participants completed the surveys in about 20 minutes and gave the completed surveys to their instructors who in turn returned them to the second author. (See the Appendix for a copy of the survey items).

\section{Measures}

The Indiana Mathematics Belief Scale is an instrument developed by Kloosterman and Stage (1992) to measure the mathematical beliefs of students. The instrument includes five Likert-type scales that is made up of six items each. The scales are intended to measure the following beliefs about mathematics and mathematics problem-solving:

Belief I: I can solve time-consuming mathematics problems

Belief II: There are word problems that cannot be solved with simple, step-by-step procedures.

Belief III: Understanding concepts is important in mathematics. 
Belief IV: Word problems are important in mathematics

Belief $V$ : Effort can increase mathematical ability.

Belief VI: Mathematics is useful in daily life.

According to Kloosterman and Stage (1992), the first belief scale was developed to measure the degree of mathematical problem difficulty based on how much time is required to solve it. This idea, Kloosterman and Stage (1992) claim, was inspired by the fact that most mathematics problems at the precollege level "require completion of 10 or more exercises so that problems which sustained thought are rare, and most precollege textbook word problems are of the 1- or 2- step variety that can be solved in one or two minutes" (p.110). The second belief scale was created with the intention of challenging the popular conception among precollege students that all mathematics problems should have rules and algorithms where you simply follow the procedure, plug in the numbers and obtain the results. The third belief scale builds on the second in that it is intended to measure students' conceptual understanding rather than learning by rote or memorizing. The fourth belief scale measures students' perspectives on the importance of word problems. It is a known fact that most students dread word problems and would rather solve algebraic problems that are decontextualized. The fifth belief scale measures how students perceive the relationship between effort and mathematical understanding and performance. This is based on Carol Dweck's fixed/growth mindset theory (Dweck, 2013; Hochanadel \& Finamore, 2015). According to this theory, a person with a fixed mindset believes that mathematical ability is inherited and so if you are not born with it, it is impossible to improve in your understanding of math. On the other hand, a person with a growth mindset believes that as long as you put in effort and work hard, you can always improve upon your performance on mathematical problems. The sixth belief scale is intended to measure the extent to which students see the application of mathematical problems to everyday life. In particular, this scale seeks to contextualize the mathematics content learned in real-life settings. Thus, this scale seeks to aid students to perceive the world through the lens of mathematics and apply the mathematics they learn to solve real world problems.

\section{RESULTS}

An exploratory factor analysis (EFA) was performed to examine the initial factor structure of the survey instrument. The Principal Component Analysis (PCA) method was used to extract the underlying factors. Indicators such as the Kaiser-Meyer-Olkin (KMO), the Bartlett test, and the correlation matrix were examined to determine the factorability of the sample data. The result of the KMO test was 0.79 which is considered good (Kaiser, 1974) and is a measure of the strength of the relationship among the items (Pett, Lackey, \& Sullivan, 2003). Also, the Bartlett test of sphericity was statistically significant $\left(x^{2}=1658.66, d f=406, p<0\right)$. This confirmed that the matrix was not an identity matrix and therefore was suitable for performing an EFA.

After initial extraction, the first ten factors had eigenvalues greater than 1. A scree plot suggested retaining five factors (see Figure 1). The five-factor solution cumulatively explained $51.24 \%$ of the variance in the data. Because we had reason to suspect that the five-factors would be correlated, we ran the EFA using oblique (promax) rotation. After rotation, the five-factor model explained 52.5\% of the data. Each factor had a primary factor loading whose absolute value was greater than 0.4 (see Table 1). The extracted factors were characterized based on item loadings. Factor 1 had six salient loading (all greater than 0.67) for items relating to hard work (items \# 8, 28, 11, 16, 22 and 4). Factor 2 had five loadings for items relating to relevance in math problems (item \# 12, 18, 3, 26 and 9). Factor 3 had six loadings for items relating to perseverance in solving difficult mathematics problems (item \# 20, 14, 24, 1, 17, and 5). Factor 4 had five loadings for items relating to conceptual understanding of mathematical facts (item \# 19,33, 25, 35, and 27). The final factor had six loadings for items relating to usefulness of math problems (item \# 13, 7, 10, 30, 21 and 32). Items with negative loading were interpreted by re-wording the negatively-worded statements. Table 2 shows the correlations between the five scales. It can be seen that all correlations were relatively small, consistent with Kloosterman and Stage's (1992) study.

Internal consistency measures was calculated for each factor. The internal consistency using Cronbach's coefficient alpha was 0.80 for factors $1 ; 0.86$ for factor $2 ; 0.64$ for factor $3,0.75$ for factor 4 , and 0.52 for factor 5. For the total Indiana Mathematical Beliefs Scale score using the 29 items that comprised the five subscales, internal consistency reliability analysis produced a Cronbach's alpha of 0.75. 


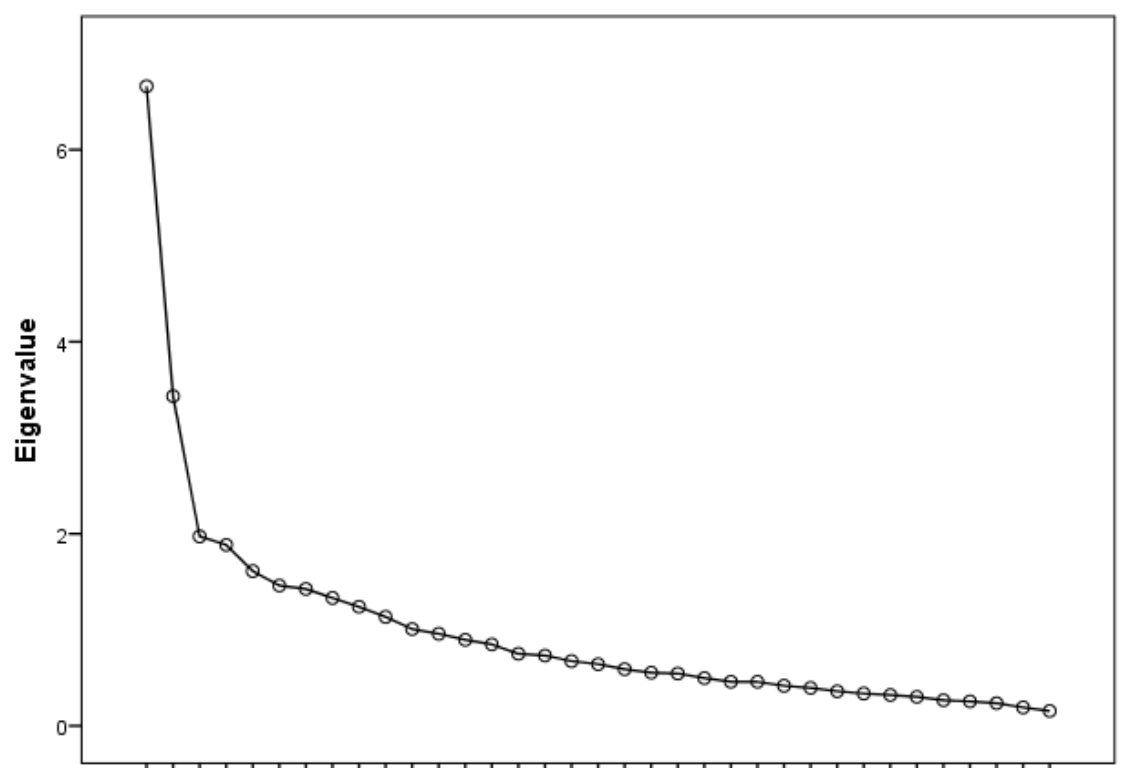

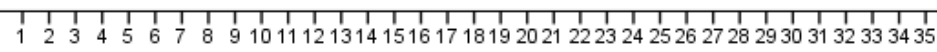

Component Number

Figure 1. Scree Plot of the 35 eigenvalues

$\underline{\text { Table 1. Items and Factor Loadings for each Indiana Mathematical Belief Scale item }}$

\begin{tabular}{|c|c|c|c|c|c|}
\hline \multirow{2}{*}{ Item Number } & \multicolumn{5}{|c|}{ Rotated Factor Loadings } \\
\hline & Factor 1 & Factor 2 & Factor 3 & Factor 4 & Factor 5 \\
\hline 8 & .858 & -.170 & .062 & -.012 & -.065 \\
\hline 28 & .800 & .071 & -.074 & .147 & -.024 \\
\hline 11 & .756 & -.042 & .051 & .176 & .040 \\
\hline 16 & .755 & .017 & -.107 & .135 & -.004 \\
\hline 22 & .720 & .229 & -.132 & -.183 & -.067 \\
\hline 4 & .675 & -.052 & .108 & -.028 & -.027 \\
\hline $12^{*}$ & .011 & -.778 & -.009 & .053 & -.100 \\
\hline 18 & -.055 & .769 & .098 & -.099 & .013 \\
\hline $3 *$ & .063 & -.740 & .018 & -.072 & .043 \\
\hline 26 & .157 & .588 & .025 & .158 & .018 \\
\hline 9 & .064 & .545 & .133 & .155 & .034 \\
\hline 6 & .086 & -.003 & .791 & -.083 & -.036 \\
\hline $20 *$ & .133 & -.042 & -.766 & .051 & .109 \\
\hline 14 & -.179 & .128 & .694 & -.067 & .019 \\
\hline $24^{*}$ & .002 & .001 & -.585 & -.337 & -.018 \\
\hline 1 & .166 & -.032 & .553 & .132 & .232 \\
\hline $17^{*}$ & -.047 & -.268 & -.468 & -.026 & .087 \\
\hline 5 & -.167 & .157 & -.323 & .063 & .275 \\
\hline $19 *$ & .071 & .042 & -.075 & -.789 & -.076 \\
\hline 33 & .086 & .017 & -.028 & .704 & .017 \\
\hline $25 *$ & .020 & .019 & -.080 & -.670 & .095 \\
\hline 35 & .147 & -.017 & -.007 & .574 & -.026 \\
\hline 27 & .090 & .278 & -.223 & .563 & -.048 \\
\hline 13 & -.092 & .176 & -.024 & -.036 & .647 \\
\hline $7 *$ & -.196 & .033 & .064 & .177 & -.557 \\
\hline 10 & .050 & -.274 & .080 & -.006 & .517 \\
\hline $30 *$ & .189 & .255 & .075 & -.278 & -.506 \\
\hline 21 & .364 & .102 & .088 & -.291 & .462 \\
\hline 32 & -.261 & .239 & -.038 & .079 & .425 \\
\hline \% Variance explained & 21.2 & 11.6 & 8.6 & 5.8 & 5.3 \\
\hline Eigenvalue & 5.6 & 1.9 & 1.5 & 1.4 & 1.3 \\
\hline Chronbach's Alpha & 0.80 & 0.86 & 0.64 & 0.75 & 0.52 \\
\hline
\end{tabular}

* Denotes negatively worded items. 
Table 2. Component Correlation Matrix

\begin{tabular}{cccccc}
\hline Component & $\mathbf{1}$ & $\mathbf{2}$ & $\mathbf{3}$ & $\mathbf{4}$ & $\mathbf{5}$ \\
\hline 1 & - & & & & \\
\hline 2 & .239 & - & & & \\
\hline 3 & .112 & .334 & - & - & - \\
\hline 4 & .261 & .381 & .293 & -.146 & \\
\hline 5 & .098 & -.129 & -.088 & & \\
\hline
\end{tabular}

\section{DISCUSSION}

The study sought to identify factor dimensions of the Indiana Mathematics Beliefs Scale administered to students enrolled in a Calculus class in a Midwestern University in the United States. An exploratory factor analysis identified five dimensions that account for $52.5 \%$ of the variance in the data. Comparing the factors in this study to those in Berkaliev \& Kloosterman (2009) and Kloosterman \& Stage (1992), we can see that Factors 1, 2, 3, 4 and 5 correspond to Effort, Usefulness, Difficult problems, Understanding, and Steps, respectively.

Table 3 shows the internal reliabilities (Cronbach's a) of the current administration of the Indiana Mathematics Belief Scale compared to the previous studies (Berkaliev \& Kloosterman, 2009; Kloosterman \& Stage, 1992). In the Kloosterman \& Stage (1992) study, the scales were administered to 273 College students enrolled in a remedial mathematics class and 244 students enrolled in an elementary mathematics methods class. Similar to the findings of Berkaliev \& Kloosterman (2009), the reliabilities from the current study were very identical to the Kloosterman \& Stage (1992) study (see Table 3). Consistent with both previous studies, the Usefulness subscale had the highest Cronbach's alpha value (0.86) whereas the Steps subscale had the least value (0.52). Thus, compared to the other four subscales, it is very clear that the Cronbach's alpha for Steps has a consistently lower value which is less than the 0.7 threshold for reliability (Bland \& Altman, 1997). It might therefore make sense to drop the Steps subscale in future studies.

Table 3. Reliabilities (Cronbach's a) for the current study, compared to the studies by Berkaliev \& Kloosterman (2009) and Kloosterman \& Stage (1992)

\begin{tabular}{|c|c|c|c|}
\hline Factor & Current Study & Berkaliev \& Kloosterman (2009) & Kloosterman \& Stage (1992) \\
\hline Effort & 0.80 & 0.89 & 0.84 \\
\hline Usefulness & 0.86 & 0.87 & 0.86 \\
\hline Difficult problems & 0.64 & 0.80 & 0.77 \\
\hline Understanding & 0.75 & 0.81 & 0.76 \\
\hline Steps & 0.52 & 0.50 & 0.67 \\
\hline
\end{tabular}

The current study offers some interesting thoughts for how the teaching and learning of mathematics should be approached. For instance, if students have a strong belief in not being able to solve time-consuming mathematical problems, they will assume that all mathematics problems should be completed in a short amount of time. When such students encounter more challenging problems, they completely tune off and move on to another problem. This is consistent with Carol Dweck's (2013) growth versus fixed mindset theory. Students in this scenario fall into the fixed mindset category. The onus is therefore on mathematics instructors to help their students develop the growth mindset and have the "can-do" mentality towards mathematics problems.

Learning mathematics is an affective process that involves attitudes, emotions and beliefs. Yet this is a dimension that is often overlooked by instructors and students. While it is important to acknowledge the need for the development of pedagogical knowledge and expertise, it is just as important to also develop and become more aware of traits that are significantly affective in nature and guided by personal beliefs.

\section{Disclosure statement}

No potential conflict of interest was reported by the authors. 


\section{Notes on contributors}

Abraham Ayebo - University of Minnesota, USA.

Amaniel Mrutu - University of Minnesota, USA.

\section{REFERENCES}

Barrow, J. A., \& Wood, K. E. (2006). Fenemma-Sherman Mathematics Attitude Scales: Instruements designmed to measure attitudes towards the learning of mathematics by females and males. Journal for research in Mathematics Education, 7(5), 324-326.

Berkaliev, Z., \& Kloosterman, P. (2009). Undergraduate engineering majors' beliefs about mathematics. School Science and Mathematics, 109(3), 175-182. https://doi.org/10.1111/j.19498594.2009.tb17953.x

Cross, D. I. (2009). Alignment, cohesion, and change: Examining mathematics teachers' belief structures and their influence on instructional practices. Journal of Mathematics Teacher Education, 12(5), 325-346. https://doi.org/10.1007/s10857-009-9120-5

Di Martino, P., \& Zan, R. (2010). 'Me and maths': towards a definition of attitude grounded on students' narratives. Journal of Mathematics Teacher Education, 13(1), 27-48. https://doi.org/10.1007/s10857009-9134-Z

Dweck, C. S. (2013). Self-theories: Their role in motivation, personality, and development. Psychology press. https://doi.org/10.4324/9781315783048

Furinghetti, F., \& Pehkonen, E. (2002). Rethinking characterizations of beliefs. In Beliefs: A hidden variable in mathematics education? (pp. 39-57). Springer, Dordrecht.

Hochanadel, A., \& Finamore, D. (2015). Fixed and growth mindset in education and how grit helps students persist in the face of adversity. Journal of International Education Research, 11(1), 47-50. https://doi.org/10.19030/jier.v11i1.9099

House, J. D. (1995). The predictive relationship between academic self-concept, achievement expectancies, and grade performance in college calculus. The Journal of Social Psychology, 135(1), 111-112. https://doi.org/10.1080/00224545.1995.9711411

Kaiser, H. F. (1974). An index of factorial simplicity. Psychometrika, 39(1), 31-36. https://doi.org/10.1007/BF02291575

Kargar, M., Tarmizi, R. A., \& Bayat, S. (2010). Relationship between mathematical thinking, mathematics anxiety and mathematics attitudes among university students. Procedia-Social and Behavioral Sciences, 8, 537-542. https://doi.org/10.1016/j.sbspro.2010.12.074

Kloosterman, P., \& Stage, F. K. (1992). Measuring beliefs about mathematical problem solving. School science and mathematics, 92(3), 109-115. https://oi.org/10.1111/j.1949-8594.1992.tb12154.x

Ma, X. (1999). A meta-analysis of the relationship between anxiety toward mathematics and achievement in mathematics. Journal for Research in Mathematics Education, 30(5), 520-540. https://doi.org/10.2307/749772

Ma, X., \& Kishor, N. (1997). Assessing the Relationship between Attitude toward Mathematics and Achievement in Mathematics: A Meta-Analysis. Journal for Research in Mathematics Education, 28(1), 26-47. https://doi.org/10.2307/749662

Maloney, E. A., Schaeffer, M. W., \& Beilock, S. L. (2013). Mathematics anxiety and stereotype threat: shared mechanisms, negative consequences and promising interventions. Research in Mathematics Education, 15(2), 115-128. https://doi.org/10.1080/14794802.2013.797744

McLeod, D. B., \& McLeod, S. H. (2002). Synthesis-beliefs and mathematics education: Implications for learning, teaching, and research. In Beliefs: A Hidden Variable in Mathematics Education? (pp. 115123). Springer, Dordrecht.

McLeod, D. B. (1992). Research on affect in mathematics education: A reconceptualization. In D. A. Grouws (Ed.), Handbook of research on mathematics teaching and learning (pp. 575- 596). New York: Macmillan.

Meece, J. L., Wigfield, A., \& Eccles, J. S. (1990). Predictors of math anxiety and its influence on young adolescents' course enrollment intentions and performance in mathematics. Journal of Educational Psychology, 82, 60 - 70. https://doi.org/10.1037/0022-0663.82.1.60 
Pajares, F., \& Graham, L. (1999). Self-efficacy, motivation constructs, and mathematics performance of entering middle school students. Contemporary educational psychology,24(2), 124-139. https://doi.org/10.1006/ceps.1998.0991

Pehkonen, E., \& Hannula, M. S. (2004). Mathematical belief research in Finland. Nordic Studies in Mathematics Education, 9(2), 23-38.

Pett, Marjorie A., Nancy R. Lackey, and John J. Sullivan. Making sense of factor analysis: The use of factor analysis for instrument development in health care research. Sage, 2003.

Pintrich, P. R. (2002). Future challenges and directions for theory and research on personal epistemology. Personal epistemology: The psychology of beliefs about knowledge and knowing, 389-414.

Sandman, R. S. (1979, April). Factors related to mathematics anxiety in the secondary school.

Paper presented at the annual meeting of the American Educational Research Association, San Francisco. Schram, C. M. (1996).

Schoenfeld, A. H. (1988). When good teaching leads to bad results: The disasters of'well-taught'mathematics courses. Educational psychologist, 23(2), 145-166. https://doi.org/10.1207/s15326985ep2302_5

Wheat, J., Tunnell, J., \& Munday, R. (1991). Predicting success in college algebra: Student attitude and prior achievement. College Student Journal, 25, 240-244.

Vanayan, M., White, N., Yuen, P., \& Teper, M. (1997). Beliefs and attitudes toward mathematics among thirdand fifth-grade students: a descriptive study. School Science and Mathematics, 97(7), 345-351. https://oi.org/10.1111/j.1949-8594.1997.tb17375.x

\section{APPENDIX}

\section{Survey Items}

1. I find I can do hard math problems if I just hang in there.

2. A person who doesn't understand why an answer to a math problem is correct hasn't really solved the problem.

3. Studying mathematics is a waste of time.

4. Ability in math increases when one studies hard.

5. Math problems can have more than one right answer.

6. I feel I can do math problems that take a long time to complete.

7. Learning to solve math problems is mostly a matter of memorizing the right steps to follow.

8. I can get smarter in math if I try hard.

9. Knowing mathematics will help me earn a living.

10. Doing math is about finding the right answer to a problem.

11. I can get smarter in math by trying hard.

12. Math is of no relevance to my life.

13. Many math problems cannot be solved by following a predetermined sequence of steps.

14. Math problems that take a long time don't bother me.

15. Most math problems are easy to solve once you figure out what type of problem they are.

16. Hard work can increase one's ability to do math.

17. If I can't solve a math problem quickly, I quit trying.

18. Mathematics is a worthwhile and necessary subject.

19. It doesn't really matter if you understand a math problem, as long as you can get the right answer.

20. I'm not very good at solving math problems that take a while to figure out.

21. Any math problem can be solved if you know the right steps to follow. 
22. Working can improve one's ability in mathematics.

23. Mathematics will not be important to me in my life's work.

24. If I can't do a math problem in a few minutes, I probably can't do it at all.

25. Getting a right answer in math is more important than understanding why the answer works.

26. I study mathematics because I know how useful it is.

27. In addition to getting a right answer in mathematics, it is important to understand why the answer is correct.

28. By trying harder, one can become smarter in math.

29. Some math problems aren't like any of the common types of problems.

30. A question that must be answered in writing is not a math problem.

31. Which answer to a math problem is correct (or best) depends on how the answer is going to be used.

32. There is no procedure to solving many math problems.

33. It is not important to understand why a mathematical procedure works as long as it gives the correct answer.

34. A math problem can often be solved correctly in several different ways.

35. Time used to investigate why a solution to a math problem works is time well spent. 